\title{
Evaluasi Kualitas Informasi Situs Web Pemerintah Kota Singkawang
}

\author{
Yoram Estomihi Arijaya*1, Melkior N.N. Sitokdana ${ }^{2}$ \\ ${ }^{1,2}$ Universitas Kristen Satya Wacana; Jl. Diponegoro No.52-60, Salatiga, \\ Kec. Sidorejo, Kota Salatiga, Jawa Tengah, 50711, Telp/fax. (+62) 298321212 \\ ${ }^{3}$ Program Studi Sistem Informasi, FTI UKSW, Salatiga \\ e-mail: ${ }^{1682016050 @ s t u d e n t . u k s w . e d u, ~}{ }^{2}$ melkior.sitokdana@uksw.edu
}

\begin{abstract}
Abstrak
Perkembangan teknologi informasi dan komunikasi menciptakan teknologi website sebagai media informasi efektif yang terhubung ke jaringan internet sehingga dapat diakses setiap saat. Pemerintah Kota Singkawang dengan alamat domain https://portal.singkawang.go.id/ turut memanfaatkan teknologi website sebagai wadah dalam memberikan layanan dan informasi bagi masyarakat, berdasarkan instruksi presiden nomor 3 tahun 2003 tentang kebijakan dan strategi national pengembangan e-Government. Tujuan dari penelitian ini adalah untuk mengevaluasi kualitas informasi dan memberikan rekomendasi kepada Pemerintah Kota Singkawang sehingga dapat meningkatkan kualitas layanan informasi yang berkualitas. Penelitian dilakukan menggunakan metode, deskripstif kualitatif dengan teknik pengumpulan data yang diperoleh melalui studi literatur, artikel, jurnal serta pengamatan langsung dari situs web Pemerintahah Kota Singkawang dan diukur menggunakan 10 (sepuluh) indikator kualitas informasi. Hasil penelitian dari evaluasi kualitas informasi pada situs web menyimpulkan bahwa Pemerintah Kota Singkawang sudah cukup baik menyediakan informasi berkualitas serta konten yang relevan dan sudah memenuhi standar minimum yang ditentukan Depkominfo. Akan tetapi masih memiliki beberapa kekurangan seperti gangguan teknis, tautan error, page not found, halaman kosong atau tidak lengkap sehingga dari kekurangan dan kelemahan tersebut diberikan rekomendasi saran untuk melakukan perbaikan dan peningkatan kualitas informasi.
\end{abstract}

Kata kunci-e-Government, Kualitas Informasi, Situs Web, Kota Singkawang

\begin{abstract}
The development of information and communication technology creates website technology as an effective information media that is connected to the internet network so that it can be accessed at any time. Singkawang City Government with a domain address https://portal.singkawang.go.id/ also utilizes website technology as a forum in providing services and information for the community, based on presidential instruction number 3 of 2003 on the policy and strategy of national e-Government development. The purpose of this study is to evaluate the quality of information and provide recommendations to the Singkawang City Government so as to improve the quality of quality information services. The research was conducted using qualitative descriptive method with data collection techniques obtained through literature studies, articles, journals and observations directly from the Singkawang City Government website and measured using 10 (ten) information quality indicators. The results of the evaluation of the quality of information on the website concluded that the Singkawang City Government has been good enough to provide quality information and relevant content and has met the minimum standards set by the Ministry of Communication and Information. However, it still has some shortcomings such as technical glitches, error links, pages not found, blank or incomplete pages so that from the shortcomings and weaknesses are given recommendations for suggestions to make improvements and improve the quality of information.
\end{abstract}


Keywords - e-Government, Information Quality, Website, Singkawang City

\section{PENDAHULUAN}

Perkembangan teknologi informasi yang semakin canggih, memasuki era revolusi industry 4.0 memberi berbagai informasi serta menyebabkan banyak perubahan besar pada kehidupan manusia modern. Untuk melakukan pertukaran informasi, maka diperlukan suatu fasilitas sebagai penghubung kepada pengguna, salah satunya website. Website sangat membantu dalam layanan publik, mempercepat penyampaian dan penerimaan informasi. Peraturan mentri komunikasi dan informatika Republik Indonesia, tentang penyelenggaraan portal dan situs web badan pemerintahan dalam rangka Penatakelolaan e-Government, pemerintah Indonesia membutuhkan sebuah website untuk mempermudah penyampaian informasi layanan publik. Kehadiran teknologi informasi berbasis online di institusi pemerintah Indonesia ditandai dengan munculnya berbagai website di setiap instansi pemerintahan yang merupakan tahap pertama dalam melaksanakan pengembangan $e$-Government.

Salah satunya instansi pada pemerintahan Kota Singkawang sudah memanfaatkan dan menggunakan website Kota Singkawang dengan alamat https://portal.singkawangkota.go.id/ sebagai sarana memberi penyampaian informasi tentang pelayanan publik, kegiatan, dokumentasi, berita di pemerintahan kota singkawang. Setelah layanan website diimplementasikan masih dijumpai permasalahan atau kelemahan dalam website, maka perlu adanya evaluasi kualitas informasi. Dikemukakan dalam beberapa penelitian Sitokdana (2015) mengatakan bahwa pada tingkat Pemerintah Daerah rata-rata Situs Web-nya berada pada tingkat pertama (persiapan), hanya sebagian kecil yang mencapai tingkat dua (pematangan), sedangkan tingkat tiga (pemantapan), dan empat (pemanfaatan) belum tercapai. Hal tersebut di pengaruhi oleh kompleksitas persoalan di Indonesia, seperti rendahnya kualitas sumber daya manusia, angka kemiskinan tinggi, kondisi perekonomian tidak stabil, dan kondisi perpolitikan Nasional semakin buruk [1].

Gullikson et al., (1999) menyatakan bahwa pada dasarnya seseorang akan menggunakan layanan website untuk mencari informasi yang cepat dan mudah diperoleh [2]. Pengguna akan merasa terpuaskan jika layanan website yang dibuka tersebut sesuai dengan persepsi tentang mutu layanan informasi yang saat ini dirasakan dan tingkat harapan masa datang. Pemanfaatan dan kegunaan website dilihat dari seberapa baik fungsi dan seberapa efektif pengguna dapat bernavigasi merupakan salah satu faktor kunci kualitas layanan website (Poon, 2002) [3].

Kualitas dari sebuah layanan website yang baik sangat mempengaruhi tingkat penggunaan layanan website. Penelitian yang dilakukan oleh DeLone \& McLean (2003) menyimpulkan bahwa kualitas informasi (information quality) dan kualitas pelayanan (service quality) berpengaruh positif terhadap tingkat kepuasaan pengguna dan intensitas penggunaan layanan suatu sistem informasi. Semakin baik kualitas layanan suatu website yang diberikan, maka semakin besar tingkat kepuasan dan semakin sering seseorang menggunakan layanan tersebut. Sedangkan semakin besar tingkat kepuasan seseorang akan suatu layanan website maka semakin tinggi intensitas seseorang menggunakan layanan tersebut[4].

Penelitian ini mencoba melakukan evaluasi kualitas informasi layanan website Kota Singkawang tentang mutu layanan website, untuk mengetahui atribut atau fitur website apa saja yang sudah baik atau masih memerlukan perbaikan agar meningkatkan mutu layanan website sehingga dapat memenuhi kebutuhan pengguna. Hasil dari penelitian ini diharapkan dapat memberikan umpan balik bagi pihak manajemen layanan website Kota Singkawang dalam perbaikan dan pengembangan website agar dapat meningkatkan kualitas layanan website Kota Singkawang sesuai harapan penggunanya. 
Penelitian ini menggunakan 10 (sepuluh) indikator dimensi kualitas informasi yaitu; Accuracy, Consistency, Timeliness, Completeness, Reliability, Availability, Relevancy, Believability, Efficiency dan Value-Added. Dengan tujuan mengukur kualitas informasi dan hasilnya akan memberikan masukan untuk perbaikan kualitas informasi pada situs Website Kota Singkawang dengan demikian pemerintah tersebut dapat memberikan layanan informasi berkualitas dan mempercepat penyampaian informasi bagi publik.

\section{TINJAUAN PUSTAKA DAN TEORI}

\subsection{Penelitian Terdahulu}

Penelitian dengan topik evuasi Situs Web Pemerintah Daerah di Indonesia bukanlah merupakan topik baru, maka beberapa penelitian terdahulu di jadikan acuan dalam penelitian ini, antara lain:

Penelitian dilakukan oleh Sitokdana, Melkior (2019) berjudul "Evaluation of the Information Quality of E-Government Websites of the Provincial Governments of Eastern Indonesia" (Case Study: NTT Province, Maluku, North Maluku, West Papua and Papua). Dalam penelitian tersebut mengatakan pemerintah Provinsi di Wilayah Indonesia Timur sejak lama memiliki Situs Web e-Government, namun dalam implementasinya masih dijumpai berbagai permasalahan, salah satunya adalah kualitas informasi yang disajikan dalam Situs Web e-Government belum cukup baik. Padahal Kualitas informasi merupakan salah satu indikator penting dalam layanan informasi. Oleh karena itu, dilakukan penelitian untuk evaluasi kualitas informasi Situs Web e-Government Pemerintah Provinsi Wilayah Indonesia Timur, yaitu: Nusa Tenggara Timur (NTT), Maluku, Maluku Utara, Papua Barat dan Papua. Masing-masing Situs Web tersebut diukur menggunakan 10 (sepuluh) dimensi kualitas informasi, yaitu Accuracy, Consistency, Timeliness, Completeness, Reliability, Availability, Relevancy, Believability, Efficiency dan Value-Added. Berdasarkan hasil evaluasi ditemukan bahwa semua Situs Web $e$ Government di Wilayah Indonesia Timur belum cukup menyediakan informasi yang berkualitas bagi publik. Oleh karena itu, direkomendasikan beberapa hal, yaitu: Pemerintah Provinsi tersebut harus senantiasa meningkatkan akurasi penyajian informasi, konsisten dalam penyajian informasi dan pastikan data selalu update dan lengkap, memastikan data selalu tersedia, meningkatkan nilai tambah dalam layanan publik dan menjadikan Situs Web sebagai medium utama layanan informasi publik [5].

Penelitian dilakukan oleh (Tabuni et al., 2019) berjudul "Evaluasi Kualitas Informasi Situs Web Pemerintah Kabupaten Jayawijaya". Dalam penelitian tersebut mengatakan Pemerintah Kabupaten Jayawijaya sejak lama memiliki Situs Web dengan nama domain http://www.jayawijayakab.go.id.

Dalam pemanfaatannya ditemukan berbagai kekurangan dan kelemahan pada Situs Web yang mengakibatkan kurang optimalnya ketersediaan data dan informasi layanan publik. Oleh karena itu dipandang perlu untuk dievaluasi dan diberikan rekomendasikan kepada para pengambil kebijakan agar melakukan langkah-langkah penyempurnaan secara taktis dan strategis. Penelitian dilakukan dengan menggunakan metode deskriptif kualitatif, yaitu mendeskripsikan dan menggambarkan isi konten Situs Web menggunakan dua instrumen, yaitu: (1) menggunakan standar isi Situs Web Pemerintah Daerah yang ditetapkan Depkominfo dan (2) menggunakan 20 (dua puluh) dimensi kualitas informasi menurut Knight \& Burn. Evaluasi tersebut dilakukan per-tanggal 1 Januari sampai 6 Februari 2019. Berdasarkan hasil Evaluasi Kualitas Informasi ditarik kesimpulan bahwa; Situs Web Pemerintah Daerah Kabupaten Jayawijaya belum cukup menyediakan informasi yang berkualitas bagi publik dan kualitas kontennya belum memenuhi standar yang ditetapkan Depkominfo. Hal tersebut dinilai dari tidak berfungsinya sebagian navigasi dan menu, ketidaktersediaan data dan informasi yang 
dibutuhkan publik dan belum konsisten dan serius dalam mengelolah Situs Web. Oleh karena itu, beberapa poin rekomendasi bagi Pemerintah Kabupaten Jayawijaya, khususnya kepada Organisasi Perangkat Daerah (OPD) yang berwenang adalah (1) Dibutuhkan komitmen yang kuat dan konsisten dalam mengelolah Situs Web, (2) Menyempurnakan navigasi dan menumenu yang belum berfungsi disesuaikan dengan regulasi, (3) Menyediakan data dan informasi layanan publik secara realtime, (4) Memastikan seluruh masyarakat dapat mengakses informasi publik di Situs Web secara efektif dan efisien. (5) Memastikan Situs Web tersebut memberikan manfaat dan value added bagi publik dan pemerintah sendiri [6].

Penelitian dilakukan oleh Sarmento, Prisca Jose Maria Bruno Alves, Melkior N. N. Sitokdana, (2019) berjudul "Evaluasi Kualitas Informasi Situs Web Pemerintah Kota Salatiga". Dalam penelitian tersebut mengatakan Pemerintah Kota Salatiga sejak lama memiliki Situs Web dengan alamat http://www.salatiga.go.id/. Dalam implementasi dan pemanfaatannya masih dijumpai berbagai permasalahan, terutama dalam hal ketersediaan kualitas informasi pada situs web. Oleh karena itu, tujuan penelitian ini adalah mengevaluasi kualitas informasi pada situs web dan memberikan rekomendasi kepada Pemerintah Kota Salatiga agar dapat meningkatkan kualitas layanan informasi yang berkualitas. Penelitian dilakukan dengan menggunakan metode deskriptif kualitatif dengan teknik pengambilan data pengamatan terhadap isi situs web dan studi literatur. Data-data yang dikumpulkan diukur menggunakan 10 indikator kualitas informasi, yaitu accuracy, consistency, timeliness, completeness, reliability, availability, relevancy, believability, efficiency, dan value-added. Berdasarkan hasil evaluasi kualitas informasi pada situs web tersebut dapat disimpulkan pemerintah Kota Salatiga sudah cukup menyediakan informasi yang berkualitas bagi publik dan memenuhi standar yang ditentukan Depkominfo. Namun, masih memiliki kekurangan dalam hal update informasi dan data secara realtime (setiap hari) dan masih kurang konsisten dalam penyajian informasi [7].

Penelitian berjudul "Evaluasi Kualitas Informasi Situs Web Pemerintah Kota Bitung" oleh Johandi et al., (2020) berdasarkan instruksi presiden nomor 3 tahun 2003 tentang kebijakan dan strategi nasional pengembangan e-Government memicu Pemerintah Kota Bitung turut serta dalam memberikan layanan teknologi informasi berupa website https://bitungkota.go.id. Penelitian ini membahas tentang evaluasi kualitas informasi berdasarkan 10 (sepuluh) indikator dimensi kualitasi informasi. Pengumpulan data penelitian diperoleh langsung dari situs web Pemerintah Kota Bitung serta kajian terhadap literatur, artikel, dan jurnal. Hasil dari penelitian menyimpulkan bahwa secara umum kualitas informasi Pemerintah Kota Bitung sudah cukup baik. Beberapa kekurangan yang ditemukan pada umumnya disebabkan oleh tautan yang error atau menuju ke halaman kosong sehingga diberikan rekomendasi untuk melakukan perbaikan dan peningkatan kualitas informasi [8].

\section{2 Landasan Teori}

Bank Dunia Bank et al., (2002) definisi e-Government merupakan : e-Government refer to the use by government agencies of information technologies (such as Wide Area Network, the internet and mobile computing) that have the ability to transform relation with citizens, business, and other arms of government [9]. Adapun definisi tersebut menegaskan bahwa penggunan e-Government oleh pemerintah sebagai sarana transformasi sesuai dengan Impres No 3 Tahun 2003, terdapat 4 (empat) konsep interaksi yang dapat menghubungkan antara pemerintah dengan masyarakat $(\mathrm{G} 2 \mathrm{C})$, pemerintah dengan pemerintah $(\mathrm{G} 2 \mathrm{G})$, pemerintah dengan bisnis (G2B), pemerintah dengan pegawai baik pegawai negeri maupun sebagai karyawan/pekerja pemerintah (G2E) lewat teknologi informasi seperti jaringan WAN, internet dan komputasi mobile.

Pengertian lain menurut (Silcock, R 2001) "e-Government is the use of technology to enchance the acces to and delivery of government services to benefit citizens, business partners and employees" [10]. Menurut United Nation Development Programme dari jurnal presentasi 
yang ditulis oleh Sari dan Wirnarno (2012:3) mendefinisikan e-Government merupakan aplikasi aplikasi teknologi informasi dan komunikasi oleh pemerintah [11]. Sedangkan menurut Holmes mendefinisikan "e-Government is the use of information technology, in particular the internet, to deliver public service in a much more convenient, customer-oriented, cost-efective, and altogether different and better way. It affects an agency's dealing with citizens, businesses, and other public agencies as well its internal business processes and employees" [12].

Manfaat pengembangan e-Government bagi pemerintah adalah (1) Memperbaiki kualitas pelayanan pemerintah kepada para stakeholder-nya baik masyarakat maupun kalangan bisnis dan industri. (2) Meningkatkan tranparansi, kontrol, dan akuntabilitas penyelenggaraan pemerintah. (3) Mengurangi biaya administrasi relasi dan interaksi. (4) Memberikan peluang bagi pemerintah untuk mendapatkan sumber pendapatan baru. (5) Menciptakan suatu lingkungan masyarakat informasi yang dapat secara cepat dan tepat menjawab berbagai permasalahan yang dihadapi. (6) Memberdayakan masyarakat dan pihak-pihak lain sebagai mitra pemerintah dalam proses pengambilan berbagai kebijakan publik secara demokratis.

Dalam pengembangan dan penerapan e-Government untuk menunjang berhasilnya pengembangan sistem e-Government dapat diukur dengan menggunakan kualitas informasi. Kualitas informasi, kualitas sistem, kualitas pelayanan, penggunaan, kepuasan pengguna, dan manfaat bersih yang dipersepsikan merupakan ukuran yang valid dari kesuksesan sistem $e$ Government [13]. Menurut DeLone \& McLean (2003) Kualitas informasi (quality of information) sangat dipengaruhi atau ditentukan oleh tiga hal yaitu relevan (relevancy), akurat (accuracy), tepat waktu (timeliness), dapat dipercaya (reliability) [4]. Knight \& Burn mendefinisikan dimensi kualitas informasi dalam beberapa indikator dengan mengutip sebagian ringkasan dimensi dari Wang \& Strong (1996) adalah sebagai berikut:2. 2.1 Table 1. Dimensi Kualitas Informasi

Tabel 1. Dimensi Kualitas Informasi [14]

\begin{tabular}{lll}
\hline No & \multicolumn{1}{c}{ Dimensi Kualitas informasi } & \multicolumn{1}{c}{ Definisi } \\
\hline 1. & Akurasi & Informasi bebas dari kesalahan \\
2. & Konsistensi & Tidak bertentangan dengan informasi sebelumnya \\
3. & Kecepatan waktu & Informasi tersedia tepat waktu \\
4. & Kelengkapan & Tidak ada bagian informasi yang hilang \\
5. & Kehandalan & Informasi dapat diandalkan \\
6. & Ketersediaan & Informasi dapat diakses setiap saat \\
7. & Relevansi & Bermanfaat dan dapat digunakan untuk saat tertentu \\
8. & Kepercayaan & Informasi dapat dipercaya dan kredibel \\
9. & Efisiensi & Informasi memudahkan tugas-tugas \\
10. & Nilai tambah & Informasi memberikan manfaat lebih \\
\hline
\end{tabular}

\section{METODE PENELITIAN}

Penelitian ini menggunakan metode penelitian kualitatif yang sifatnya deskriptif. Menurut Siyoto \& Sodik (2015) pendekatan kualitatif adalah suatu proses penelitian dan pemahaman yang berdasarkan pada metodologi yang menyelidiki suatu fenomena sosial dan masalah manusia [15]. Dalam konteks penelitian ini dilakukan deskripsi kualitas informasi terhadap isi konten Situs Web e-Government Pemerintah Kota Singkawang dengan alamat https://portal.singkawangkota.go.id/ menggunakan sumber data sekunder, yaitu kajian terhadap literatur, artikel, jurnal serta pengamatan dan penelusuran secara mendalam. Tahapan yang digunakan dalam penelitian, yaitu: (1) Studi Pustaka, dilakukan tinjauan Pustaka terkait 
penelitian terdahulu dan teori tentang e-Government dan kualitas informasi, (2) Pengumpulan data, dilakukan tinjauan terhadap situs Web e-Government Kota Singkawang dengan melakukan pengamatan terdahap data-data dan kualitas informasi serta memastikan kesesuaian dengan standar yang ditetapkan Depkominfo, (3) Analisis data, dilakukan analisis data menggunakan dua instrument, yaitu: mengukur Situs Web berdasarkan standar yang ditetapkan Depkominfo dan melakukan analisis Situs Web menggunakan dimensi kualitas informasi. Dalam penelitian ini menggunakan 10 indikator dalam ringkasan dimensi kualitas informasi yang dikemukakan oleh Knight \& Burn (2005), 10 indikator dimensi kualitas informasi yang akan digunakan yaitu Akurasi, Konsistensi, Ketepatan Waktu, Kelengkapan, Kehandalan, Ketersediaan, Relevansi, Kepercayaan, Efisiensi, Nilai tambah [16]. Evaluasi Kualitas Informasi Situs Web tersebut dilakukan per-tanggal 1 November sampai 7 Desember 2020.

\section{HASIL DAN PEMBAHASAN}

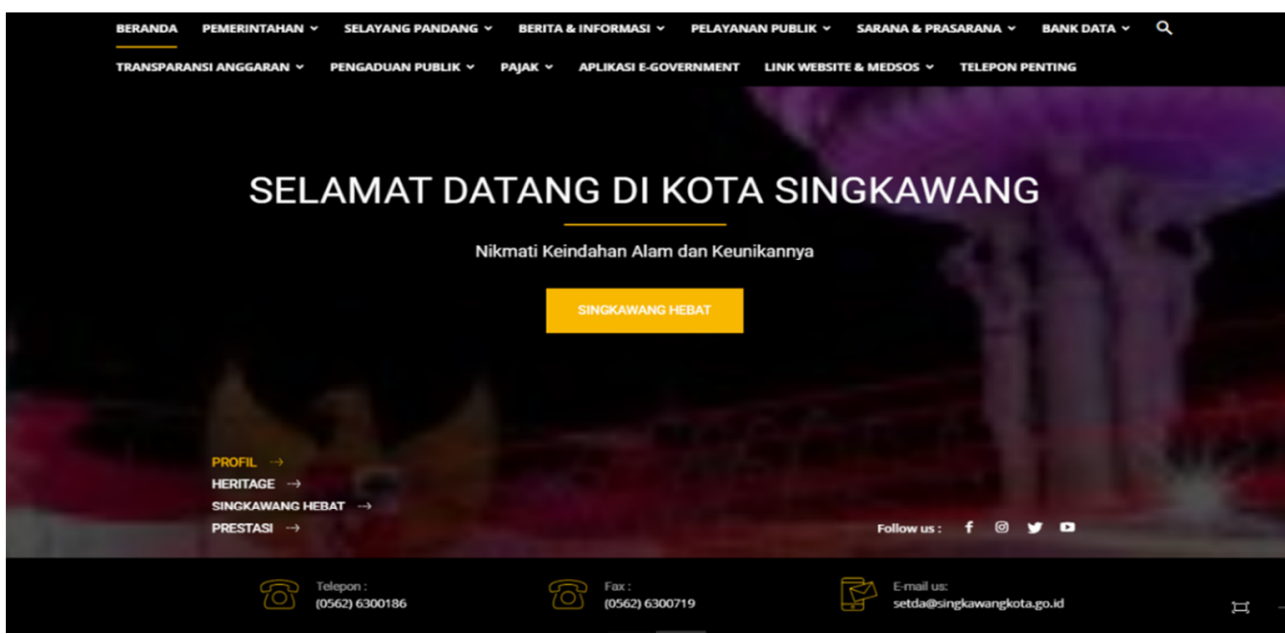

Gambar 1. Tampilan Situs Web Pemerintah Kota Singkawang

Pada Gambar 1 diatas merupakan Situs Web yang dikelola langsung oleh Pemerintah Kota Singkawang terdapat 14 (empat belas) menu pada halaman Situs Web Pemerintah Kota Singkawang, yaitu; Beranda, Pemerintahan, Selayang Pandang, Berita \& Informasi, Pelayanan Publik, Sarana \& Prasarana, Bank Data, Transparansi Anggaran, Pengaduan Publik, Pajak, Aplikasi E-Government, Link Website \& Medsos, Telepon Penting, dan Pencarian. Secara detail dapat dijelaskan pada Table 2 di bawah ini.

Tabel 2. Gambaran Situs Web Kota Singkawang

\begin{tabular}{|c|c|c|c|}
\hline No & Nama Menu & Sub Menu & Penjelasan \\
\hline 1 & Beranda & Profil & $\begin{array}{l}\text { Beranda adalah tampilan depan dari situs } \\
\text { web, Pada halaman ini menampilkan } \\
\text { profil berita terbaru, social media, menu } \\
\text { layanan (Beranda, Pemerintahan, } \\
\text { Selayang Pandang, Berita \& Informasi, } \\
\text { Pelayanan Publik, Sarana \& Prasarana, } \\
\text { Bank Data, Transparansi Anggaran, } \\
\text { Pengaduan Publik, Pajak, Aplikasi E- } \\
\text { Government, Link Website \& Medsos, } \\
\text { Telepon Penting), pencarian, tautan link }\end{array}$ \\
\hline
\end{tabular}




\begin{tabular}{|c|c|c|c|}
\hline & & & social media, kontak. \\
\hline \multirow[t]{7}{*}{2} & \multirow[t]{7}{*}{ Pemerintahan } & Lambang Daerah & $\begin{array}{l}\text { Menjelaskan tentang makna warna, } \\
\text { gambar dan moto dalam lambang daerah. }\end{array}$ \\
\hline & & $\begin{array}{l}\text { Visi \& Misi Singkawang } \\
\text { Hebat }\end{array}$ & Menjelaskan tentang Visi dan Misi \\
\hline & & Struktur Organisasi & $\begin{array}{l}\text { Menjelaskan gambaran sturktur organisasi } \\
\text { dalam bentuk gambaran. }\end{array}$ \\
\hline & & Profil Walikota & $\begin{array}{l}\text { Menjelaskan tentang profil pribadi } \\
\text { walikota dan moto. }\end{array}$ \\
\hline & & Profil Wakil Walikota & $\begin{array}{l}\text { Menjelaskan tentag profil pribadi wakil } \\
\text { walikota. }\end{array}$ \\
\hline & & Profil Sekda & Menjelaskan tentang profil pribadi Sekda. \\
\hline & & Prestasi \& Inovasi & $\begin{array}{l}\text { Menjelaskan tentang prestasi dan inovasi } \\
\text { dari kota singkawang dengan } \\
\text { mencantumkan bukti penghargaan. }\end{array}$ \\
\hline \multirow[t]{3}{*}{3} & \multirow[t]{3}{*}{$\begin{array}{l}\text { Selayang } \\
\text { Pandang }\end{array}$} & Sejarah & $\begin{array}{l}\text { Menjelaskan tentang sejarah terbentuknya } \\
\text { Kota Singkawang. }\end{array}$ \\
\hline & & Geografis & $\begin{array}{l}\text { Menjelaskan tentang cuaca, iklim serta } \\
\text { letak (Astronomi, } \\
\text { Administratif) batas. }\end{array}$ \\
\hline & & Demografi & $\begin{array}{l}\text { Menjelaskan tentang Laporan Data } \\
\text { Kependudukan seperti } \quad \text { kuantitas } \\
\text { penduduk, kuantitas keluarga dan } \\
\text { kepemillikan dokumen. }\end{array}$ \\
\hline \multirow[t]{6}{*}{4} & \multirow[t]{6}{*}{$\begin{array}{l}\text { Berita \& } \\
\text { Informasi }\end{array}$} & Media Center & $\begin{array}{l}\text { Tautan link Media Center Singkawang } \\
\text { adalah pusat informasi dan fasilitas } \\
\text { kebutuhan publik terhadap informasi. }\end{array}$ \\
\hline & & $\begin{array}{l}\text { Protokol Dokumentasi } \\
\text { Pimpinan }\end{array}$ & $\begin{array}{l}\text { Tautan link Protokol Dokumentasi } \\
\text { Pimpinan. }\end{array}$ \\
\hline & & JDIH & Tautan link JDIH. \\
\hline & & Info Pangan & $\begin{array}{l}\text { Tautan link DISDAGINKOPUKM berupa } \\
\text { informasi harga bahan pokok Kota } \\
\text { Singkawang. }\end{array}$ \\
\hline & & Info Covid 19 & Tautan link Web Covid-19. \\
\hline & & Pengumuman & Tautan link Pengumuman. \\
\hline \multirow[t]{5}{*}{5} & \multirow{5}{*}{$\begin{array}{l}\text { Pelayanan } \\
\text { Publik }\end{array}$} & Permohonan Informasi & \multirow[t]{2}{*}{ Tautan link aplikasi PPID. } \\
\hline & & PPID & \\
\hline & & $\begin{array}{l}\text { Rekomendasi Menara } \\
\text { Telekomunikasi }\end{array}$ & $\begin{array}{l}\text { Tautan link aplikasi SIDALMENTEL } \\
\text { Kota Singkawang. }\end{array}$ \\
\hline & & $\begin{array}{l}\text { Pengujian Kendaraan } \\
\text { Bermotor/KIR }\end{array}$ & $\begin{array}{l}\text { Tautan link Penguji Kendaraan } \\
\text { Bermotor/KIR berupa buku saku. }\end{array}$ \\
\hline & & Sistem Perizinan Berusaha & Tautan link aplikasi website BKPM. \\
\hline
\end{tabular}

Arijaya, et., al [Evaluasi Kualitas Informasi Situs Web Pemerintah Kota Singkawang] 


\begin{tabular}{|c|c|c|c|}
\hline & & $\begin{array}{l}\text { Terintegrasi Secara } \\
\text { Elektronik (OSS) }\end{array}$ & \\
\hline & & $\begin{array}{l}\text { Aplikasi Cerdas Layanan } \\
\text { Perizinan Terintegerasi } \\
\text { untuk Publik (SiCantik) }\end{array}$ & Tautan link aplikasi SICANTIK. \\
\hline & & SiHebat Android & Tautan link aplikasi SIHEBAT. \\
\hline & & Perpustakaan Digital & Tautan link aplikasi Perpustakaan Digital. \\
\hline & & $\begin{array}{l}\text { Perpustakaan Digital } \\
\text { Android }\end{array}$ & Tautan link aplikasi IsingkawangHebat. \\
\hline & & Layanan Kependudukan & Tautan link Layanan Kependudukan. \\
\hline & & $\begin{array}{l}\text { Pengadaan Barang dan } \\
\text { Jasa }\end{array}$ & $\begin{array}{l}\text { Tautan link Web LPSE Singkawang } \\
\text { Hebat. }\end{array}$ \\
\hline & & $\begin{array}{l}\text { Pendaftaran Peserta Didik } \\
\text { Baru }\end{array}$ & Tautan link PPDB. \\
\hline 6 & Sarana \& & Hotel & Tautan link website pasti ke Singkawang \\
\hline & Prasarana & Wisata & berisi list terbaru tempat wisata, kuliner, \\
\hline & & Even & hotel dan event terbaru. \\
\hline & & Kuliner & \\
\hline & & Galery Dekranasda & $\begin{array}{l}\text { Tautan link website Dekranasda Kota } \\
\text { Singkawang. }\end{array}$ \\
\hline & & Pasar & Tautan link Pasar. \\
\hline & & $\begin{array}{l}\text { Terminal Angkutan } \\
\text { Penumpang }\end{array}$ & $\begin{array}{lll}\text { Tautan link } & \text { Terminal Angkutan } \\
\text { Penumpang. } & & \\
\end{array}$ \\
\hline & & Rumah Sakit & $\begin{array}{l}\text { Tautan link Rumah Sakit berupa daftar list } \\
\text { Rumah Sakit, alamat, dan kontak. }\end{array}$ \\
\hline & & Puskesmas & $\begin{array}{l}\text { Tautan link Puskesmas berupa daftar list } \\
\text { Puskesmas dan kontak. }\end{array}$ \\
\hline & & Fasilitas Olahraga & Tautan link Fasilitas Olahraga. \\
\hline & & Sekolah & $\begin{array}{l}\text { Tautan link Sekolah berupa daftar list } \\
\text { sekolah. }\end{array}$ \\
\hline & & Perguruan Tinggi & $\begin{array}{l}\text { Tautan link Perguruan Tinggi berupa } \\
\text { daftar list Perguruan Tinggi, alamat, dan } \\
\text { kontak. }\end{array}$ \\
\hline & & CCTV Kota & Tautan link CCTV KOTA. \\
\hline & & Wifi Publik & Tautan link Wifi Publik. \\
\hline 7 & Bank Data & Data Kite & Tautan link aplikasi Data Kite. \\
\hline & & Satu Data Indonesia & Tautan link aplikasi Satu Data Indonesia. \\
\hline & & Download & $\begin{array}{l}\text { Tautan link dokumen RPJMD Kota } \\
\text { Singkawang tahun 2018-2022. }\end{array}$ \\
\hline 8 & $\begin{array}{l}\text { Transparansi } \\
\text { Anggaran }\end{array}$ & $\begin{array}{l}\text { Transparansi Anggaran } \\
2019\end{array}$ & $\begin{array}{l}\text { Menjelaskan tentang transparansi } \\
\text { anggaran pemerintah Kota Singkawang } \\
\text { tahun 2019 dengan mencantumkan } \\
\text { lampiran. ringkasan anggaran pendapatan } \\
\text { dan belanja daerah. }\end{array}$ \\
\hline & & $\begin{array}{l}\text { Transparansi Realisasi } \\
\text { Anggaran } 2019\end{array}$ & $\begin{array}{l}\text { Mencantumkan lampiran hasil laporan } \\
\text { realisasi anggaran pemerintah Kota } \\
\text { Singkawang tahun } 2019 .\end{array}$ \\
\hline & & $\begin{array}{l}\text { Transparansi Anggaran } \\
2020\end{array}$ & $\begin{array}{lll}\text { Menjelaskan tentang } & \text { transparansi } \\
\text { anggaran pemerintah Kota } & \text { Singkawang }\end{array}$ \\
\hline
\end{tabular}




\begin{tabular}{|c|c|c|c|}
\hline & & & $\begin{array}{l}\text { tahun } 2020 \text { dengan mencantumkan } \\
\text { lampiran ringkasan anggaran pendapatan } \\
\text { dan belanja daerah. }\end{array}$ \\
\hline \multirow[t]{3}{*}{9} & \multirow[t]{3}{*}{$\begin{array}{l}\text { Pengaduan } \\
\text { Publik }\end{array}$} & Whistleblowing System & $\begin{array}{l}\text { Tautan link Aplikasi Whistleblowing } \\
\text { System. }\end{array}$ \\
\hline & & LAPOR & Tautan link aplikasi LAPOR. \\
\hline & & $\begin{array}{l}\text { SIADU (Pengaduan } \\
\text { Perizinan) }\end{array}$ & Tautan link aplikasi SIADU. \\
\hline \multirow[t]{11}{*}{10} & \multirow[t]{11}{*}{ Pajak } & Pajak Bumi dan Bangunan & \multirow{11}{*}{$\begin{array}{l}\text { Menjelaskan tentang standar pelayanan } \\
\text { pajak seperti produk layanan, dasar } \\
\text { hukum, persyaratan, waktu layanan, biaya } \\
\text { / tarif administrasi, produk, pengelolaan } \\
\text { pengaduan, jenis layanan lainnya. }\end{array}$} \\
\hline & & BPHTB & \\
\hline & & Pajak Hiburan & \\
\hline & & Pajak Hotel & \\
\hline & & Pajak Restoran & \\
\hline & & Pajak Air dan Tanah & \\
\hline & & Pajak Parkir & \\
\hline & & $\begin{array}{l}\text { Pajak Sarang Burung } \\
\text { Walet }\end{array}$ & \\
\hline & & Pajak Reklame & \\
\hline & & Pajak Penerangan Jalan & \\
\hline & & Pajak Mineral dan Batuan & \\
\hline 11 & $\begin{array}{l}\text { Aplikasi E- } \\
\text { Government }\end{array}$ & Aplikasi E-Governtment & $\begin{array}{l}\text { Berisi daftar Link Aplikasi } \\
\text { Governtment. }\end{array}$ \\
\hline \multirow[t]{7}{*}{12} & \multirow[t]{7}{*}{$\begin{array}{l}\text { Link Website } \\
\& \text { Medsos }\end{array}$} & Website OPD & $\begin{array}{l}\text { Daftar link Organisasi Perangkat Daerah / } \\
\text { Unit Kerja Pemerintahan } \\
\text { Singkawang. }\end{array}$ \\
\hline & & Website Kecamatan & $\begin{array}{l}\text { Berisi daftar link Website Kecamatan } \\
\text { Singkawang. }\end{array}$ \\
\hline & & Website Kelurahan & $\begin{array}{l}\text { Berisi daftar link Website Keluarahan } \\
\text { Singkawang. }\end{array}$ \\
\hline & & PDAM Gunung Poteng & Link Website PDAM Gunung Poteng. \\
\hline & & KPU Singkawang & Link Website KPU Kota Singkawang. \\
\hline & & Email & $\begin{array}{l}\text { Berisi daftar alamat email ODP dan } \\
\text { Panduan penggunaan email. }\end{array}$ \\
\hline & & Medsos OPD & $\begin{array}{l}\text { Link tautan media social KOMINFO } \\
\text { (Facebook, Instagram, Twitter). }\end{array}$ \\
\hline 13 & $\begin{array}{l}\text { Telepon } \\
\text { Penting }\end{array}$ & Telepon Penting & Berisi daftar nomor telepon darurat. \\
\hline 14 & Pencarian & $\begin{array}{l}\text { Search Engine } \\
\text { Optimization (SEO) }\end{array}$ & Mesin pencarian pada website. \\
\hline
\end{tabular}

Pada bagian ini dilakukan evaluasi kualitas informasi pada Situs Web e-Government Pemerintah Kota Singkawang menggunakan 10 (Sepuluh) dimensi kualitas informasi yang dipilih dan ambil dari 20 (Dua puluh) dimensi kualitas informasi pada table diatas, Adapun dimensi kualitas informasi yang dipilih dan diambil diantaranya yaitu Akurasi, Konsistensi, Kecepatan Waktu, Kelengkapan, Kehandalan, Ketersediaan, Relevansi, Kepercayaan, Efisiensi dan Nilai Tambah. Berikut hasil penilaian dari evaluasi dimensi kualitas informasi pada situs web Pemerintah Kota Singkawang. 
Tabel 3. Evaluasi Kualitas Informasi Situs Web Pemerintahan Kota Singkawang

\begin{tabular}{|c|c|c|c|}
\hline No. & Indikator & $\begin{array}{rr}\text { Evaluasi } \\
\end{array}$ & Rekomendasi \\
\hline 1. & Akurasi & $\begin{array}{l}\text { Secara umum informasi yang disajikan sudah } \\
\text { baik dengan mencantumkan sumbernya juga } \\
\text { terdapat dokumentasi pada berita dan } \\
\text { informasi yang disajikan. }\end{array}$ & 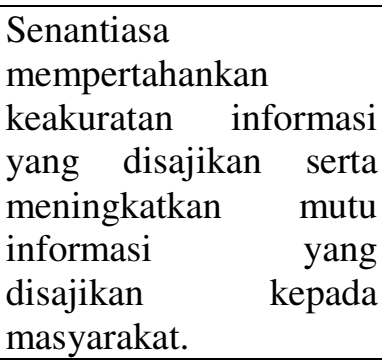 \\
\hline 2. & Konsistensi & $\begin{array}{l}\text { Informasi yang disajikan belum cukup } \\
\text { konsisten karena kurang terupdate setiap saat } \\
\text { seperti pada menu berita dan informasi } \\
\text { bagian (pengumuman) masih kosong belum } \\
\text { terdapat informasi, menu pelayanan publik } \\
\text { bagian (perpustakaan digital, layanan } \\
\text { kependudukan, pendaftaran peserta didik } \\
\text { baru) belum terdapat informasi dan adanya } \\
\text { gangguan teknis, menu sarana dan prasarana } \\
\text { bagian (pasar, terminal angkutan penumpang, } \\
\text { fasilitas olahraga dan CCTV kota) masih } \\
\text { kosong belum terdapat informasi, menu } \\
\text { aplikasi e-government bagian (e-planning, } \\
\text { email kota singkawang, DAPO } \\
\text { DIKDASMEN, SIM Tunjangan, SPM } \\
\text { Kesehatan, profil kesehatan dan } \\
\text { SIMPOLDAGRI) terdapat gangguan teknis, } \\
\text { menu link website \& medos bagian (website } \\
\text { kelurahan) pada setiap link websitenya masih } \\
\text { kosong belum terdapat informasi. }\end{array}$ & $\begin{array}{l}\text { Penyajian informasi } \\
\text { harus konsisten juga } \\
\text { melengkapi seluruh } \\
\text { data yang masih kosong } \\
\text { dan belum terdapat } \\
\text { infromasi serta diupdate } \\
\text { setiap saat. }\end{array}$ \\
\hline 3. & $\begin{array}{l}\text { Kecepatan } \\
\text { Waktu }\end{array}$ & $\begin{array}{l}\text { Informasi yang disajikan secara umum sudah } \\
\text { baik, dan informasi dalam bentuk berita terus } \\
\text { diupdate dan diperbaharui setiap waktu, } \\
\text { transparansi dokumen yang dipublikasikan } \\
\text { diperbaharui setiap ada pembaharuan } \\
\text { tersedia. }\end{array}$ & $\begin{array}{l}\text { Mempertahankan } \\
\text { konsistensi penyajian } \\
\text { informasi dan } \\
\text { mendokumentasikan } \\
\text { informasi yang lampau } \\
\text { agar tidak hilang } \\
\text { sehingga dapat } \\
\text { dijadikan sebagai bahan } \\
\text { perbandingan dan } \\
\text { pembangunan lebih } \\
\text { lanjut. }\end{array}$ \\
\hline 4. & Kelengkapan & $\begin{array}{l}\text { Informasi data tidak diperbaharui setiap } \\
\text { waktu. }\end{array}$ & $\begin{array}{l}\text { Mempertahankan dan } \\
\text { menyempurnakan } \\
\text { informasi yang sudah } \\
\text { adaryantiasa } \\
\text { melakukan senapdate } \\
\text { informasi setiap hari. }\end{array}$ \\
\hline 5. & Kehandalan & $\begin{array}{l}\text { Informasi yang tersedia merupakan informasi } \\
\text { yang dapat di andalkan karena sumber yang } \\
\text { jelas dari pemerintah, relevan dan selalu ter- }\end{array}$ & $\begin{array}{l}\text { Senantiasa memberikan } \\
\text { informasi } \\
\text { berbobot bagi publik }\end{array}$ \\
\hline
\end{tabular}




\begin{tabular}{|c|c|c|c|}
\hline & & update dan diperbaharui secara rutin. & $\begin{array}{l}\text { serta update informasi } \\
\text { dilakukan secara rutin. }\end{array}$ \\
\hline 6. & Ketersediaan & $\begin{array}{l}\text { Informasi yang tersedia dapat diakses setiap } \\
\text { saat terkecuali gangguan teknis seperti } \\
\text { gangguan internet atau perbaikan dari } \\
\text { pemerintah. }\end{array}$ & $\begin{array}{l}\text { Memastikan informasi } \\
\text { senantiasa tersedia dan } \\
\text { pemberitahuan jika } \\
\text { mengalami perbaikan } \\
\text { dari pemerintah. }\end{array}$ \\
\hline 7. & Relevansi & $\begin{array}{l}\text { Informasi yang disajikan sudah cukup baik } \\
\text { dan relevan bagi publik seperti tersedianya } \\
\text { informasi pada menu Selayang Pandang } \\
\text { (Sejarah, Geografis, Demografi), menu } \\
\text { Sarana \& Prasarana (Hotel, Wisata, Event, } \\
\text { Kuliner Dsb), Infomasi COVID 19, kegiatan } \\
\text { kota dan transparansi Anggaran sehingga } \\
\text { informasi dapat bermanfaat bagi berbagai } \\
\text { kalangan. }\end{array}$ & $\begin{array}{l}\text { Senantiasa } \\
\text { menyediakan informasi } \\
\text { yang relevan dan } \\
\text { berbobot bagi publik. }\end{array}$ \\
\hline 8. & Kepercayaan & $\begin{array}{l}\text { Setiap informasi yang disajikan disertai } \\
\text { sumbernya dan secara rutin terupdate dan } \\
\text { diperbaharui sehingga dapat dipercaya } \\
\text { ditambah dengan informasi bermanfaat dan } \\
\text { relevan mampu meningkatkan minat } \\
\text { masyarakat untuk mengakses situs web. }\end{array}$ & $\begin{array}{lr}\text { Senantiasa } & \text { memberikan } \\
\text { informasi } & \text { yang } \\
\text { berbobot } & \text { serta } \\
\text { memastikan } & \\
\text { kelengkapan } & \text { informasi } \\
\text { sehingga } & \text { dapat } \\
\text { meningkatkan publik } \\
\text { terhadap situs web. }\end{array}$ \\
\hline 9. & Efisiensi & $\begin{array}{l}\text { Informasi pada situs web saat ini cukup } \\
\text { efektif bagai layanan public karena } \\
\text { kelengkapan, manfaat dan informasi yang } \\
\text { relevan serta secara rutin diperbaharui bisa } \\
\text { digunakan untuk mepentingan } \\
\text { riset/perumusan masalah juga dapat } \\
\text { memudahkan layanan masyarakat publik, } \\
\text { khusunya kalangan akademis, praktisi dan } \\
\text { internal. }\end{array}$ & $\begin{array}{l}\text { Mempertahankan, } \\
\text { meningkatkan dan } \\
\text { senantiasa memberikan } \\
\text { informasi } \\
\text { bermanfaat, relevan } \\
\text { serta dapat diakses } \\
\text { dengan mudah. }\end{array}$ \\
\hline 10. & Nilai tambah & $\begin{array}{l}\text { Informasi pada situs web memberikan nilai } \\
\text { tambah bagi publik, karena terdapat } \\
\text { informasi dan aplikasi yang mempermudah } \\
\text { layanan masyarakat publik seperti SIHEBAT, } \\
\text { SICANTIK, ISingkawangHebat, WHISTLE } \\
\text { BLOWING SYSTEM, LAPOR, SIADU dan } \\
\text { E-LHKPN, sehingga dapat menjadi nilai } \\
\text { tambah bagi masyarakat publik. }\end{array}$ & $\begin{array}{lr}\text { Meningkatkan } & \text { serta } \\
\text { memberi layanan sesuai } \\
\text { dengan } & \text { kebutuhan } \\
\text { masyarakat } & \text { publik } \\
\text { sehingga } & \text { informasi } \\
\text { yang } & \text { disajikan } \\
\text { senantiasa memberikan } \\
\text { nilai tambah dan } \\
\text { manfaat } \\
\text { publik. }\end{array}$ \\
\hline
\end{tabular}

Dengan demikian berdasarkan hasil evaluasi kualitas informasi menggunakan 10 (sepuluh) dimensi pada Table 3 menunjukan bahwa situs Web Pemerintah Kota Singkawang secara umum sudah cukup baik dalam menyediakan informasi namun masih terdapat kekurangan pada konsitensi dan kelengkapan penyajian informasi bagi kepentingan layanan publik. Oleh karena itu, dalam Table 3 diatas merumuskan rekomendasi yang dapat dijadikan sebagai sarana pengembangan dan peningkatan Situs Web Pemerintahan Kota Singkawang. 


\section{KESIMPULAN DAN SARAN}

Berdasarkan hasil dan evaluasi menggunakan 10 (sepuluh) dimensi Kualitas Informasi pada Situs Web e-Government Pemerintah Kota Singkawang dapat ditarik kesimpulan bahwa Situs Web Pemerintah Kota Singkawang sudah cukup baik menyediakan informasi dan konten yang sudah memenuhi standar minimum yang ditentukan Depkominfo serta berkualitas bagi publik. Akan tetapi masih memiliki beberapa kekurangan seperti gangguan teknis, tautan error, page not found, halaman kosong atau tidak lengkap sehingga dari kekurangan tersebut beberapa hal yang menjadi saran dari peneliti adalah meningkatkan akurasi dalam penyajian informasi serta konsisten dalam penyajian informasi memastikan informasi dapat ditampilkan dengan lengkap dan jelas juga meningkatkan nilai tambah seperti layanan bagi kebutuhan publik yang relevan sehingga meningkatkan minat publik dan menjadikan Situs Web https://portal.singkawangkota.go.id/ sebagai wadah layanan informasi masyarakat Kota Singkawang.

\section{DAFTAR PUSTAKA}

[1] M. N. N. Sitokdana, 2015, "Evaluasi Implementasi eGovernment pada Situs Web Pemerintah Kota Surabaya, Medan, Banjarmasin, Makassar dan Jayapura," J. Buana Inform., No.16, No. 4, pp. 289-300, doi: 10.24002/jbi.v6i4.461.

[2] S. Gullikson, R. Blades, M. Bragdon, S. McKibbon, M. Sparling, and E. G. Toms, 1999, "The Impact of Information Architecture On Academic Web Site Usability," Electron. Libr., Vol. 17, No. 5, pp. 293-304, doi: 10.1108/02640479910330714.

[3] S. Poon, 2002, "Esdlife of Hong Kong E- Government Application With an E- Business Spirit a Pplication With an E-B Usiness S Pirit," Am. Conf. Inf. Syst., Vol. 86, [Online]. Available: http://aisel.aisnet.org/cgi/viewcontent.cgi?article=1445\&context=amcis 2002 .

[4] W. H. DeLone and E. R. McLean, 2003, "The DeLone and McLean Model of Information Systems Success: A Ten-Year Update,” J. Manag. Inf. Syst., Vol. 19, No. 4, pp. 9-30, doi: 10.1080/07421222.2003.11045748.

[5] M. N. N. Sitokdana, 2019, "Evaluation of The Information Quality of E-Government Websites of The Provincial Governments of Eastern Indonesia (Case Study: NTT Province, Maluku, North Maluku, West Papua and Papua)," Vol. 100, No. I coi, pp. 231-241, doi: 10.2991/icoi-19.2019.40.

[6] G. Tabuni, T. Priyantoro, S. Web, P. Daerah, and K. Informasi, 2019, “Evaluasi Kualitas Informasi Situs Web Pemerintah Kabupaten Jayawijaya Evaluation for Quality of Information The Jayawijaya," pp. 35-41.

[7] and P. F. T. Sarmento, Prisca Jose Maria Bruno Alves, Melkior N. N.. Sitokdana, 2019, “Evaluasi Kualitas Informasi Situs Web Pemerintah Kota Salatiga,” Singaraja-Bali,.

[8] D. Johandi, F. Kambey, and M. Sitokdana, 2020, “Evaluasi Kualitas Informasi Situs Web Pemerintah Kota Bitung,” Semin. Nas. Teknol. Komput. ..., Vol. 10, pp. 7-12, [Online]. Available: http://seminar-id.com/prosiding/index.php/sainteks/article/view/396. 
[9] W. Bank, I. Trust, and C. Services, 2002. "The World Bank New-Economy Sector Study Electronic Government and Governance : Lessons for Argentina,” No. July,

[10] B. Y. R. Silcock, 2018, "Mercy Education System of The Americas," Hist. Mercy Educ., pp. 88-101, [Online]. Available: http://mercyedu.org/history/.

[11] W. A. Sari, Kusuma Dewi Arum, dan Winarno, 2012. "Implementasi E-Government System Dalam Upaya Peningkatan Clean and Good Governance di Indonesia," Vol. XI, No. 1, pp. 1-19,

[12] D. Tapscott et al., 2001. Praise for eGov.

[13] Y. S. Wang and Y. W. Liao, 2008, "Assessing eGovernment Systems Success: A Validation of The DeLone and McLean Model of Information Systems Success," Gov. Inf. Q., Vol. 25, No. 4, pp. 717-733, doi: 10.1016/j.giq.2007.06.002.

[14] D. M. Wang, Richard Y., \& Strong, 1996, "Beyond accuracy: What Data Quality Means to Data Consumers," J. Manag. Inf. Syst., Vol. 12, No. 4, pp. 5-34, doi: 10.1080/07421222.1996.11518099.

[15] S. Siyoto and M. A. Sodik, 2015, Dasar Metodologi Penelitian. Literasi Media Publishing.

[16] S. A. Knight and J. Burn, 2005, "Developing A Framework For Assessing Information Quality On The World Wide Web," Informing Sci., Vol. 8, pp. 159-172, doi: 10.28945/493. 